\title{
Carbapenemase-producing Enterobacteriaceae in a group of Polish travelers returning from South and South-East Asia, June 2017 - June 2018. Environment- or healthcare-associated?
}

\author{
Matylda Kłudkowska ${ }^{1,2, B, D, F \oplus}{ }^{\oplus}$, Łukasz Augustyn Pielok ${ }^{1, B, D \oplus}{ }^{\circ}$ Marta Wrońska ${ }^{2, B}{ }^{\oplus}$, \\ Hanna Tomczak $2,3, A, F(\mathbb{0}$ \\ ${ }^{1}$ Medical University, Poznań, Poland \\ ${ }^{2} \mathrm{H}$. Święcicki University Hospital, Central Microbiology Laboratory, Poznań, Poland \\ ${ }^{3}$ Department of Genetics and Pharmaceutical Microbiology, University of Medical Sciences, Poznań, Poland \\ A - Research concept and design, B - Collection and/or assembly of data, C - Data analysis and interpretation, \\ $D$ - Writing the article, $E$ - Critical revision of the article, $F$ - Final approval of article \\ Kłudkowska M, Pielok ŁA, Wrońska M, Tomczak H. Carbapenemase-producing Enterobacteriaceae in a group of Polish travelers returning from \\ South and South-East Asia, June 2017 - June 2018. Environment- or healthcare-associated? Ann Agric Environ Med. $2019 ; 26(3)$ : $405-408$. \\ doi: 10.26444/aaem/106113
}

\begin{abstract}
Introduction. Carbapenemase-producing Enterobacteriaceae have spread rapidly through the countries and continents to become a global concern. One of the main reservoirs of NDM-1 positive strains from the Enterobacteriaceae family is the Indian subcontinent (Bangladesh, Pakistan, India).

Materials and method. During June 2017 - June 2018, rectal swab samples were collected routinely in all patients returning to Poland from South and South-East Asia. During molecular examinations gene bla $a_{\mathrm{NDM}-1}$ encoding NDM-1 carbapenemase was detected.

Results. 31 patients were examined after returning to Poland from a trip to South and South-East Asia. The presence of New Delhi Metallo- $\beta$-lactamase-1 producing Escherichia coli and Klebsiella pneumoniae was confirmed in three patients (9.7\%) returning to Poland from travels to India. All the positive patients were hospitalized during the trip in a New Delhi hospital. Conclusions. Digestive tract carriage of NDM in a group of Polish travelers is a significant health and epidemiological problem. The study confirms the necessity for screening for carbapenemase-producing Enterobacteriaceae (CPE), particularly among travellers. Rectal swabs should be collected in every case of patients returning from international trips, and the possibility of environment-associated infections should be emphasized.
\end{abstract}

Key words

carbapenemase; carbapenems; New Delhi Metallo- $\beta$-lactamase; NDM; CPE; travelers' diarrhea

\section{INTRODUCTION}

Carbapenems, generally known as a last-line antibiotics, are a group of $\beta$-lactams applied in critically ill patients infected with multidrug resistant bacteria [1]. Therefore, the emergence of the resistance to carbapenems in Enterobacteriaceae has become a global concern against which the world is slowly becoming helpless. The most important mechanism is considered the production of the hydrolyzing enzymes carbapenemases, with a great role played by the New Delhi Metallo- $\beta$-lactamase (NDM) [1]. This type of antibiotic resistance was first described in 2008 in the case of Swedish tourist after returning from India. During the trip, the man was hospitalized in New Delhi hospital [2]. At the same time, very similar strains from patients in India, Bangladesh, Pakistan and the UK were isolated [3]. In 2009-2012, NDMproducing Enterobacteriaceae rapidly spread through the countries and continents $[3,4]$.

Global transmission of the carbapenemase-producing Enterobacteriaceae (CPE) is also related to the number of international tourist arrivals, which increased to the

Address for correspondence: Hanna Tomczak, Central Microbiology Laboratory, H. Święcicki University Hospital, Poland

E-mail: hannatomczak@interia.pl

Received: 21.11.2018; accepted: 01.04.2019; first published: 11.04.2019 enormous number of 1,322 million travelers in 2017 [5]. The first case of NDM-producing strains described in Poland - E. coli ST410 - was imported from the Congo in 2011 [6]. The detection of NDM-1-producing Klebsiella pneumoniae in the Central Laboratory of Microbiology of the H. Święcicki University Hospital in Poznań, Poland, in November 2012, was the beginning of an alarming outbreak in Poland resulting in 374 cases in $2012-2014$ [6].

The rapid spread of these strains is also due to the location of encoding genes on the plasmids, which can be easily transmitted through bacteria, and even overcome the species barriers [2].

\section{MATERIALS AND METHOD}

During June 2017 - June 2018, rectal swab samples were collected routinely from all patients returning from South and South-East Asia, and hospitalized in the Clinic of Tropical and Parasitic Diseases of Poznań Medical University, Poland. All patients completed a questionnaire on age, gender, travel destination, length of stay, travel purposes, hospitalization during the trip, the main clinical symptoms observed after returning to Poland. In all the patients with gastrointestinal disorders, differential diagnosis for an infectious agents 
was also performed, including parasitological stool examination, and stool cultures for Salmonella spp., Shigella spp., Campylobacter spp., enterotoxigenic E. coli, and vibrio bacteria. All examinations performed in the hospitalized patients were performed routinely and did not require agreement of the Bioethic Committee.

All the rectal swabs were cultured on ChromIDCarba - selective chromogenic medium for the screening of carbapenemase-producing Enterobacteriaceae (bioMerieux). Identification of isolated bacteria was performed by the VITEK $^{\circ}$ MS - an automated mass spectrometry microbial identification system that uses MALDI-TOF technology (bioMerieux). For the preliminary testing of MBL, KPC and OXA-48 production, a disc diffusion method was performed, as recommended by the European Committee on Antimicrobial Susceptibility Testing (EUCAST) [7]. The production of carbapenemases was confirmed by the biochemical CARBA Test (Diagnostics) based on the direct detection of carbapenem hydrolysis. The final confirmation with the PCR techniques was made by the National Reference Centre for Susceptibility Testing, National Medicines Institute, Warsaw, Poland. For drug susceptibility testing, the VITEK2 system (bioMerieux) was used. MICs for meropenem, imipenem, tigecycline, amikacin and gentamicin were also confirmed by using MIC Test Strip (Liofilchem). MIC for colistin was specified by the MIC-Strip Colistin - broth microdilution method (MERLIN).

\section{RESULTS}

During the study period, a total of 31 patients - 17 male and 14 female, returning from South and South-East Asia, were included. Median age was 35 years (range $18-60$ ). The most popular travel destinations in the study group was India (52\%), Thailand (16\%), Thailand/ Vietnam/Cambodia (16\%). Duration of the trip ranged between two weeks and six months. The main travel purposes were tourism/recreation and business. Seven of the 31 patients (23\%) were hospitalized during the trip in local hospitals, mostly because of diarrhea, including four travelling to India. The most common cause of hospitalization after returning to Poland was persistent diarrhea, abdominal pain and fever.

NDM-positive bacteria were detected in three patients admitted to the Clinic after returning from India. During molecular examinations gene bla $a_{\mathrm{NDM}-1}$ encoding New Delhi Metallo- $\beta$-lactamase-1 (NDM-1) was detected in all positive patients. Characteristics of the travellers who acquired NDM during trip and the molecular testing results are summarized in Table 1. Of the three travellers with detected CPE, all had been hospitalized in India during the trip because of massive diarrhea. The time of hospitalization ranged from $3-6$ days. Patients were treated symptomatically.

Dynamics over time in the appearance of the strains were also analyzed and are summarized in Table 2. In the case of Traveler 1, immediately after return to Poland, Escherichia coli and Klebsiella pneumoniae, both producing NDM-1 carbapenemases, were cultured. One week later, only Escherichia coli NDM-positive was cultured. After one month, the examination revealed two phenotypically distinct Escherichia coli NDM-positive strains. Two months after the first examination, the patient's rectal swabs were negative. In the case of Traveller 2, on admission to hospital Escherichia
Table 1. Characteristics of travellers who acquired NDM-producing Enterobacteriaceae during the trip and molecular testing results

\begin{tabular}{|c|c|c|c|c|c|c|c|}
\hline No. & Age & Gender & $\begin{array}{l}\text { Travel } \\
\text { destina- } \\
\text { tion }\end{array}$ & $\begin{array}{c}\text { Travel } \\
\text { purposes }\end{array}$ & $\begin{array}{c}\text { Hospi- } \\
\text { talised } \\
\text { during trip }\end{array}$ & Species & Gene \\
\hline 1 & 27 & M & India & Business & Yes & $\begin{array}{c}\text { Escherichia coli } \\
\text { Klebsiella } \\
\text { pneumoniae }\end{array}$ & $\begin{array}{l}b / a_{\mathrm{NDM}-1} \\
b l a_{\mathrm{NDM}-1}\end{array}$ \\
\hline 2 & 28 & $\mathrm{~F}$ & India & $\begin{array}{c}\text { Tourism } \\
\text { and } \\
\text { recreation }\end{array}$ & Yes & Escherichia coli & $b l a_{\mathrm{NDM}-1}$ \\
\hline 3 & 31 & M & India & Business & Yes & $\begin{array}{l}\text { Escherichia coli } \\
\text { Escherichia coli } \\
\text { Escherichia coli }\end{array}$ & $\begin{array}{l}b l a_{\mathrm{NDM}-1} \\
b l a_{\mathrm{NDM}-1} \\
b l a_{\mathrm{NDM}-1}\end{array}$ \\
\hline
\end{tabular}

coli NDM-positive was cultured. After one week the same strain was observed. Examination one month later revealed two phenotypically distinct Escherichia coli strains. After 2.5 months, rectal swabs were negative. In the case of Traveller 3 , three different Escherichia coli NDM-1-positive strains were observed. Negative results were obtained after one month.

Table 2. Dynamics over time in the appearance of the NDM-1-producing Enterobacteriaceae in three positive carriers

\begin{tabular}{ccccc}
\hline No. & On admission & After one week & After one month & $\begin{array}{c}\text { Negative } \\
\text { result }\end{array}$ \\
\hline 1 & $\begin{array}{c}\text { Escherichia coli } \\
\text { Klebsiella pneumoniae }\end{array}$ & Escherichia coli & $\begin{array}{l}\text { Escherichia coli } \\
\text { Escherichia coli }\end{array}$ & 2 months \\
\hline 2 & Escherichia coli & Escherichia coli & $\begin{array}{l}\text { Escherichia coli } \\
\text { Escherichia coli }\end{array}$ & 2.5 months \\
\hline & Escherichia coli & $\begin{array}{l}\text { Escherichia coli } \\
\text { Escherichia coli }\end{array}$ & $\begin{array}{l}\text { Escherichia coli } \\
\text { Escherichia coli }\end{array}$ & negative \\
\hline
\end{tabular}

Traveller 1.27-year-old male admitted to the Clinic because of numerous loose stools, with suspicion of parasitic infection. The first symptoms appeared during his business trip to India where he spent two weeks, and reappeared two weeks before admission. Several times he had consumed meals with raw vegetables and fruit in local restaurants and fast foods chains. Because of diarrhea, he spent three days in a hospital in New Delhi, where he was treated symptomatically.

After return to Poland, the gastrointestinal symptoms relapsed. On admission day, patient was afebrile. Physical examination revealed the presence of slight abdominal tenderness, as well as enhanced bowel movements. The parasitic stool examination revealed the presence of numerous Giardia intestinalis cysts and trophozoites. Lack of effectiveness of treatment with metronidazole, tilbroquinolonum and albendazole was observed, and the infection persisted for four months.

Investigation of rectal swabs revealed Escherichia coli and Klebsiella pneumoniae both producing NDM1 carbapenemases. After one month, two phenotypically distinct strains Escherichia coli also producing NDM-1 carbapenemases were isolated. Patient's rectal swabs were negative in two months after the first examination.

Traveller 2. 28-year-old female with gastrointestinal disorders hospitalized after returning from India and Sri Lanka. She alternatively backpacked all over the India and Sri Lanka in difficult conditions for five months. Almost all the time 
she consumed meals from local fast foods oputlets, often undercooked, with raw fruit and vegetables. During the trip, the patient was hospitalized in New Delhi because of high fever, headache, abdominal pain, and urinary tract infection.

On her return to Poland, she reported numerous loose stools, abdominal pain, flatulence and nausea. Parasitological stool examination revealed massive Giardia intestinalis (cysts and trophozoites) and Blastocystis spp. (cysts and vacuolar, avacuolar, multivacuolar, ameboidal forms) infection. The presence of Salmonella spp., Shigella spp. and Yersinia spp. in the faeces was excluded. To eradicate protozoal infection, treatment with tynidazole and tilbroquinolonum was implemented. The first negative result of a parasitological examination was observed after three days, with no further relapses.

Investigation of the rectal swabs revealed one strain of NDM-positive Escherichia coli. The same strain was cultured after a week. After one month, two phenotypically distinct Escherichia coli strains were isolated. The first negative result was obtained after 2.5 months.

Traveller 3. 31-year-old male hospitalized after returning to Poland from a business trip to India, where he spent two weeks. He consumed raw vegetables and fruit from local markets several times. During the stay, patient was hospitalized in New Delhi because of massive diarrhea and abdominal pain. The symptoms persisted after returning to Poland. On admission, physical examination revealed enhanced bowel movements. Parasitological stool testing revealed no parasites, but large a amount of leukocytes. The presence of Salmonella spp., Shigella spp. and Yersinia spp. in the feaces was excluded. Gastrointestinal infection was suspected and treatment with tilbroquinolonum implemented.

Rectal swabs examination revealed the presence of three different strains of NDM-positive Escherichia coli. The same strains were cultured after one week. The first negative result was obtained after one month.

\section{DISCUSSION}

Digestive tract carriage of NDM in a group of Polish travelers is a significant health and epidemiological problem. From June 2017 - June 2018 the presence of NDM-producing Enterobacteriaceae was confirmed in three of the 31 patients (9.7\%). Only NDM-1-producing Escherichia coli and Klebsiella pneumoniae were isolated. All the NDM-positive patients had travelled to India. During the trip, they were hospitalized in a different hospitals in New Delhi. They had all consumed meals with raw fruit and vegetables prepared by locals in fast food outlets and restaurants. After return to Poland, the patients were hospitalized due to travellers' diarrhea.

Carbapenemase-producing Enterobacteriaceae in Polish patients returning from South and South-East Asia were detected in $9.7 \%$ of the study group. In other scientific studies, these values are much lower. In total of 574 travelers, including 57 visiting India, CPE was detected in three cases of patients returning from India (5.3\%) - two OXA ${ }_{181}$ E. coli and one NDM-1 E. coli [8]. In a group of 2001 Dutch travelers, CPE was observed in five patients returning from Asia (0.25\%), but outside the Indian subcontinent - Enterobacter cloacae IMI-2, E. coli OXA-244, Klebsiella pneumoniae OXA-48, E. coli NDM-1/2, and E. coli NDM-7 [9]. In a total of 88 Danish, 205 German and 370 Dutch travelers, multi-drug resistant strains were isolated, but no cases of CPE [10-12]. In the currenst study, the longest time between the first positive and the first negative results study was 2.5 months. Similar data were obtained among French travellers [8]. In a case of Dutch travelers, one of OXA-244 strains persisted for up to six months after returning from the trip [9].

Most cases of CPE carriers described in the literature are associated with hospitalization during the trip [3]. The hands of healthcare personnel play a significant role in transmission of CPE between patient and hospital environment [13]. Furthermore, the transmission of CPE in healthcare institutions and the hospital water environment, mostly drains/ traps, sinks and faucets, are very important [14]. In the current study, three NDM-positive patients were hospitalized during the trip in a different hospitals in New Delhi. This observation supports the claim of healthcare-associated infection. However, two out of three NDM-positive patients were also infected with Giardia intestinalis, a parasite strongly connected with environmental transmission. The most of human infections are due to consumption of contaminated food (fruit, vegetables) or tap water containing cysts. Co-occurrence of CPE and Giardia intestinalis strongly suggest environmental-associated infection, considering that the risk factors were present in all the patients. Additionally, results published by Walsh et al. indicate the presence of the $b l a_{\mathrm{NDM}-1}$ gene in drinking water, sewage and water reservoirs in New Delhi. The bla ${ }_{\mathrm{NDM}-1}$ gene was detected in 51 of 171 water samples taken from open water reservoirs and street channels, whereas among 50 drinking water samples, two contained the bla ${ }_{\mathrm{NDM}-1}$ gene [15].

Carbapenemase-producing Enterobacteriaceae was also evaluated from ready-to-eat vegetables in China [16]. In 2012, the World Health Organization reported 626 million people in India practice "open" defecation. This directly affects the pollution of the environment by multi-drug resistant strains and the spread of carriers in the population of the Indian continent. Furthermore, good climatic conditions, such as high humidity and temperature, cause a higher risk of infection with pathogenic strains [17]. The indication of a direct source of infection among patients infected with NDM-1-producing strains seems to be very difficult. This fact is further complicated by the lack of screening for carbapenemase-producing strains in patients entering medical institutions in India.

Travellers' diarrhea (TD) is one of the most common causes of hospitalization after returning from international trips, and is characterized by three factors: susceptibility to enteric bacteria, viruses and parasites, residence in a developing country, and travel to a tropical or semi-tropical region with a low level of hygiene $[18,19]$. Differential diagnosis should be considered in moderate and severe TD cases [20]. Furthermore, $5-10 \%$ of patients with travellers' diarrhea develop chronic functional bowel diseases or post-infectious irritable bowel syndrome [19]. The most important causative agents of TD are bacteria, viruses and parasites. Among the latter, the most common are protozoa, especially Giardia intestinalis.

One of the main reservoirs of NDM-1 positive strains from the Enterobacteriaceae family is the Indian subcontinent (Bangladesh, Pakistan, India) [2, 21]. The creation of a reservoir of NDM-1 strains in this region of the world is due to an inadequate antibiotic policy, overcrowding and poor socio-economic conditions [22, 23, 24]. Analysis of the sale of antibiotics in India in 2007-2012 by McGettigan P. et al. shows the scale of the presence of unapproved medicines on the Indian pharmaceutical market. Of the formulations 
containing more than one antibiotic (FDC - fixed-dose combination) as many as $64 \%$ have not been approved by the Central Drugs Standard Control Organization (CDSCO) [25]. In 2014, the insufficient control over the quantity and quality of commonly sold antibiotics forced India to introduce prescription-only medicines. The list approved by CDSCO includedd 24 antibiotics, i.e. carbapenems [22].

The high epidemiological potential associated with the common carriage of NDM-1 positive strains, and the increased flow of patients and tourists from endemic areas to various countries, caused epidemics worldwide [24]. A list of available publications from 2009-2012 presented by Berrazeg M et al. showed the scale of the spread of CPE and their main imports from Indian and Balkan countries [26]. The epidemiological situation in Poland also reflects the rapid spread of NDM-producing bacteria. In 2012 - 2014, a total of $502 \mathrm{CPE}$ isolates from 374 patients were confirmed [6].

An estimated, approximately 100 million of the Indian population are carriers of the NDM-1-producing Enterobacteriaceae strains [15]. Although the carriage does not require eradication, it can cause difficult to treat systemic infections [27]. Statistics show that 25,000 people die in Europe due to infections caused by MDRO (Multidrug Resistance Organism) [28]. With the lack of new generations of antibiotics in perspective, and resistance to "last-line drugs", i.e. carbapenems, existing treatment regimens may be insufficient.

\section{CONCLUSIONS}

This study confirms the necessity of the screening for CPE, especially among travellers. Rectal swabs should be collected in every case of patients returning from international trips, particularly from the Indian subcontinent. Furthermore, the possibility of environment-associated infections should be emphasized. The epidemiological situation in the world caused by the unbelievably fast CPE spread requires increased vigilance from specialists and close cooperation between microbiologists and physicians. Hospitalized CPE carriers pose a threat to other patients. The risk of transmission of these extremely dangerous strains in the hospital environment has also been demonstrated, and the consequences may be vast, because we live in a post-antibiotic era.

\section{REFERENCES}

1. Hsu L-Y, Apisarnthanarak A, Khan E, Suwantarat N, et al. Carbapenemresistant Acinetobacterbaumannii and Enterobacteriaceae in South and Southeast Asia. Clin Microbiol Rev. 2017; 30: 1-22.

2. Kumarasamy KK, Toleman MA, Walsh TR, et al. Emergence of a new antibiotic resistance mechanism in India, Pakistan, and the UK: a molecular, biological, and epidemiological study. Lancet Infect Dis. 2010; 10(9): 597-602.

3. Johnson AP, Woodford N. Global spread of antibiotic resistance: the example of New Delhi metallo- $\beta$-lactamase (NDM)-mediated carbapenem resistance. J Med Microbiol. 2013; 62(Pt 4): 499-513.

4. Bushnell G, Mitrani-Gold F, Mundy LM. Emergence of New Delhi metallo- $\beta$-lactamase type 1-producing Enterobacteriaceae and nonEnterobacteriaceae: global case detection and bacterial surveillance. Int J Infect Dis. 2013; 17(5): 325-33.

5. United Nations World Tourism Organization. World Tourism Barometer. 2018: 16. http://cf.cdn.unwto.org/sites/all/files/pdf/unwto_ barom18_01_january_excerpt_hr.pdf.

6. Baraniak A, Izdebski R, Fiett J, et al. NDM-producing Enterobacteriaceae in Poland, 2012-14: inter-regional outbreak of Klebsiella pneumoniae ST11 and sporadic cases. J Antimicrob Chemother. 2016; 71(1): 85-91.

7. EUCAST, 2017. EUCAST guideline for the detection of resistance mechanisms and specific resistances of clinical and/or epidemiological importance. Version 2.0. http://www.eucast.org/fileadmin/src/media/ PDFs/EUCAST_files/Resistance_mechanisms/EUCAST_detection_ of_resistance_mechanisms_170711.pdf.

8. Ruppé E, Armand-Lefèvre L, Estellat C, et al. Acquisitionof carbapenemase-producing Enterobacteriaceae by healthy travellers to India, France, February 2012 to March 2013. Euro Surveill. 2014; 19(14). pii: 20768

9. Van Hattem JM, Arcilla MS, Bootsma MCJ, et al. Prolonged carriage and potential onward transmission of carbapenemase-producing Enterobacteriaceae in Dutch travelers. Future Microbiol. 2016; 11: 857-64.

10. Lausch KR, Fuursted K, Larsen CS, et al. Colonisation with multiresistant Enterobacteriaceae in hospitalised Danish patients with a history of recent travel: a cross-sectional study. Travel Med Infect Dis. 2013; 11(5): 320-3.

11. Lübbert C, Straube L, Stein C, et al. Colonization with extendedspectrum beta-lactamase-producing and carbapenemase-producing Enterobacteriaceae in international travelers returning to Germany. Int J Med Microbiol. 2015; 305(1): 148-56.

12. Paltansing S, Vlot JA, Kraakman ME, et al. Extended-spectrum $\beta$-lactamase-producing Enterobacteriaceae among travelers from the Netherlands. Emerg Infect Dis. 2013; 19(8): 1206-13.

13. Grabowski ME, Kang H, Wells KM, et al. Provider Role in Transmission of Carbapenem-Resistant Enterobacteriaceae. Infect Control Hosp Epidemiol. 2017; 38(11): 1329-34.

14. Kizny Gordon AE, Mathers AJ, Cheong EYL, et al. The Hospital Water Environment as a Reservoir for Carbapenem-Resistant Organisms Causing Hospital-Acquired Infections - A Systematic Review of the Literature. Clin Infect Dis. 2017; 64(10): 1435-44.

15. Walsh TR, Weeks J, Livermore D M, et al. Dissemination of NDM-1 positive bacteria in the New Delhi environment and its implications for human health: an environmental point prevalence study. Lancet Infect Dis. 2011; 11(5): 355-62.

16. Liu BT, Zhang XY, Wan SW, et al. Characteristics of CarbapenemResistant Enterobacteriaceae in Ready-to-Eat Vegetables in China. Front Microbiol. 2018; 9: 1147.

17. Nordmann P. Carbapenemase-producing Enterobacteriaceae: overview of a major public health challenge. Med Mal Infect. 2014; 44(2): 51-6.

18. Paschke C, Apelt N, Fleischmann E, et al. Controlled study on enteropathogens in travellers returning from the tropics with and without diarrhoea. Clin Microbiol Infect. 2011; 17: 1194-1200.

19. De la Cabada Bauche J, DuPont HL. New Developments in Traveler's Diarrhea. Gastroenterol Hepatol. 2011; 7(2): 88-95.

20. Riddle MS, Connor BA, Beeching NJ, et al. Guidelines for the prevention and treatment of travelers'diarrhea: a graded expert panel report. J Travel Med. 2017; 24(suppl_1): S57-S74.

21. MacFadden DR, Bogoch II, Brownstein JS, et al. A passage from India: association between air traffic and reported cases of New Delhi Metallobeta-lactamase 1 from 2007 to 2012. Travel Med Infect Dis. 2015; 13(4): 295-99.

22. Laxminarayan R, Chaudhury RR. Antibiotic resistance in India: drivers and opportunities for action. PLoS Med. 2016; 13(3): e1001974.

23. Ganguly NK, Arora NK, Chandy SJ, et al.Global Antibiotic Resistance Partnership (GARP) - India Working Group. 2011. Rationalizing antibiotic use to limit antibiotic resistance in India. Indian J Med Res. 2011; 134: 281-94.

24. Nordmann P, Poirel L. (2014). The difficult-to-control spread of carbapenemase producers among Enterobacteriaceae worldwide. Clin Microbiol Infect. 2014; 20(9): 821-30.

25. McGettigan P, Roderick P, Kadam A, et al. Reserve antibiotics in India: challenges for WHO stewardship. Lancet Glob Health. 2017; 5(11):1075-76.

26. Berrazeg M, Diene SM, Medjahed L, et al. New Delhi Metallo-betalactamase around the world: an eReview using Google Maps. Euro Surveill. 2014; 19(20): 20809.

27. Karczewski M, Tomczak H, Piechocka-Idasiak I, et al. Is Multiresistant Klebsiella pneumoniae New Delhi Metallo-beta-Lactamase (NDM-1) a New Threat for Kidney Transplant Recipients? Transplant Proc. 2014; 7(46): 2409-10.

28. Marston HD, Dixon DM, Knisely JM, et al. Antimicrobial Resistance. JAMA. 2016 Sep 20; 316(11): 1193-1204. 